\title{
Vitamin E tocotrienol supplementation improves lipid profiles in chronic hemodialysis patients
}

This article was published in the following Dove Press journal:

Vascular Health and Risk Management

27 November 2013

Number of times this article has been viewed

\section{Zulfitri A Mat Daud \\ Boniface Tubie ${ }^{2}$ \\ Marina Sheyman ${ }^{2}$ \\ Robert Osia ${ }^{2}$ \\ Judy Adams ${ }^{2}$ \\ Sharon Tubie ${ }^{2}$ \\ Pramod Khosla'}

'Department of Nutrition and Food Science, Wayne State University,

Detroit, MI, USA; ${ }^{2}$ Great Lake Dialysis

Clinic, LLC, Detroit, MI, USA
Correspondence: Pramod Khosla 3002 Science Hall, Department of Nutrition and Food Science, Wayne State University, Detroit, MI 48202, USA

Tel +l 3/35770448

Email aa0987@wayne.edu
Purpose: Chronic hemodialysis patients experience accelerated atherosclerosis contributed to by dyslipidemia, inflammation, and an impaired antioxidant system. Vitamin E tocotrienols possess anti-inflammatory and antioxidant properties. However, the impact of dietary intervention with Vitamin E tocotrienols is unknown in this population.

Patients and methods: A randomized, double-blind, placebo-controlled, parallel trial was conducted in 81 patients undergoing chronic hemodialysis. Subjects were provided daily with capsules containing either vitamin E tocotrienol-rich fraction (TRF) (180 mg tocotrienols, $40 \mathrm{mg}$ tocopherols) or placebo ( $0.48 \mathrm{mg}$ tocotrienols, $0.88 \mathrm{mg}$ tocopherols). Endpoints included measurements of inflammatory markers (C-reactive protein and interleukin 6), oxidative status (total antioxidant power and malondialdehyde), lipid profiles (plasma total cholesterol, triacylglycerols, and high-density lipoprotein cholesterol), as well as cholesteryl-ester transfer protein activity and apolipoprotein A1.

Results: TRF supplementation did not impact any nutritional, inflammatory, or oxidative status biomarkers over time when compared with the baseline within the group (one-way repeated measures analysis of variance) or when compared with the placebo group at a particular time point (independent $t$-test). However, the TRF supplemented group showed improvement in lipid profiles after 12 and 16 weeks of intervention when compared with placebo at the respective time points. Normalized plasma triacylglycerols (cf baseline) in the TRF group were reduced by $33 \mathrm{mg} / \mathrm{dL}(P=0.032)$ and $36 \mathrm{mg} / \mathrm{dL}(P=0.072)$ after 12 and 16 weeks of intervention but no significant improvement was seen in the placebo group. Similarly, normalized plasma high-density lipoprotein cholesterol was higher $(P<0.05)$ in the TRF group as compared with placebo at both week 12 and week 16. The changes in the TRF group at week 12 and week 16 were associated with higher plasma apolipoprotein A1 concentration $(P<0.02)$ and lower cholesteryl-ester transfer protein activity $(P<0.001)$.

Conclusion: TRF supplementation improved lipid profiles in this study of maintenance hemodialysis patients. A multi-centered trial is warranted to confirm these observations.

Keyword: vitamin, tocotrienol-rich fraction, lipid profiles, hemodialysis, end-stage renal disease, nutrition intervention

\section{Introduction}

End-stage renal disease (ESRD) patients on chronic hemodialysis (HD) experience a higher risk for atherosclerotic vascular disease; cardiac death accounts for approximately $50 \%$ of all-cause mortality, ${ }^{1}$ which is $15-30$ times higher than an age-matched general population. ${ }^{2,3}$ The increased cardiovascular risk in this setting, however, cannot be exclusively explained by traditional cardiovascular risk factors alone. Instead, a 
combination of various factors, especially malnutritioninflammation complex syndrome, oxidative stress, and dyslipidemia, are implicated. ${ }^{4-6}$

Patients on HD treatment often present with malnutritioninflammation complex syndrome characterized by coexistence of protein-energy malnutrition and inflammation pertaining to dialysis-related factors, disease processes, various comorbidities, nutrient loss, and poor nutritional intake. ${ }^{7}$ Chronic systemic inflammation, which is commonly found in $30 \%-50 \%$ of ESRD patients exacerbates oxidant production. This is aggravated by low intake of antioxidants, secondary to malnutrition and dietary restrictions in this population. ${ }^{8}$ In fact, low circulating plasma levels of antioxidants have been shown to correlate with carotid atherosclerosis in ESRD patients. ${ }^{9}$ Equally noteworthy, unadjusted analyses of 4D (Die Deutsche Diabetes Dialyse Studie) study revealed that HD patients in the lowest plasma vitamin E ( $\alpha$-tocopherol) quartile had a $79 \%$ higher risk of stroke and $31 \%$ higher risk of all-cause mortality as compared with their counterpart in the highest quartile; however, this was confounded by malnutrition. ${ }^{10}$

Additionally, in ESRD patients on dialysis, dyslipidemia is highly prevalent due to delayed catabolism of triglyceriderich apolipoprotein B (apoB, containing lipoproteins), which subsequently leads to elevated triacylglycerol (TAG) and low plasma high-density lipoprotein cholesterol (HDLC). ${ }^{11}$ In a study of a large cohort of incident dialysis patients $(n=21,893)$, it has been shown that dyslipidemia present in $82 \%$ of the population was predominantly manifest as elevated TAG (52\%) and very low-density lipoprotein (VLDL) (52\%), and decreased HDL (51\%). ${ }^{12}$ Furthermore, accumulating evidence indicates that the concentration of plasma apolipoprotein A1 (ApoA1) and lecithin-cholesterol acyl-transferase are decreased, ${ }^{13,14}$ which in turn impedes HDL-mediated reverse cholesterol transport, ${ }^{15}$ a process of disposing excessive cholesterol from extrahepatic tissues and blood vessel walls. Taken together, a combination of oxidative stress, lipid disorders, and inflammation in this population is highly conducive for atherogenesis by promoting LDL oxidation, monocyte activation, endothelial injury, and consequently accumulation of lipids in the artery wall. ${ }^{15}$

Dietary intervention may be potentially beneficial in improving inflammatory status, correcting oxidative stress, and the observed dyslipidemia. However, there is paucity of information regarding the impact of dietary interventions with nutrients possessing antioxidant, anti-inflammatory, or lipid altering properties to correct these problems in the HD population.
Tocotrienols (TT) are dietary compounds that have gained increasing scientific scrutiny. TT are members of the Vitamin E family, which also includes tocopherols (TP). Vitamin $\mathrm{E}$ is comprised of eight different isomers (four TP and four TT) designated $\alpha-, \beta-, \gamma-$, and $\delta$, characterized by different numbers and positions of the methyl group attached on the chromanol ring. TT are the unsaturated members of the vitamin E family, found primarily in palm fruit oil, rice bran, and annatto. In the US diet, however, TP, particularly $\gamma$-TP, is the most abundant form of vitamin $\mathrm{E}$, derived primarily from plant seeds and vegetable oils. ${ }^{16}$

Comparisons of antioxidant activities amongst vitamin $\mathrm{E}$ family members in rat liver microsomes have revealed that TT exhibits 40- to 60-fold higher activities against lipid peroxidation $\left(\mathrm{Fe}^{2+}+\right.$ ascorbate and $\mathrm{Fe}^{2+}+\mathrm{NADPH}$ induced $)$ and greater radical scavenging potency than TP. ${ }^{17,18}$ However, in vivo, antioxidative properties of TT could be limited by physiological processes (eg, absorption, distribution, metabolism, and excretion), but TT have been found to be as equally potent as TP. ${ }^{19,20}$ More importantly, TT also play a role beyond their known antioxidant activity - ie, they possess an anti-inflammatory property which has been shown to inhibit lipopolysaccharide-induced secretion of interleukin (IL)-6 and tumor necrosis factor in macrophages, ${ }^{21}$ and decreased C-reactive protein (CRP) in human volunteers. ${ }^{22}$ Additionally, TT may also confer cardioprotective effects by improving lipid profiles (reduced total cholesterol and TAGs), ${ }^{23,24}$ and lower oxidation of LDL cholesterol. ${ }^{25}$

To our knowledge, there are no reported TT studies in HD patients, whereas 17 TP trials have been reported, albeit with inconclusive results. ${ }^{26}$ The majority of these studies were open label, aimed at improving oxidative stress, while only three studies used a randomized controlled trial design that included 95 patients cumulatively. Of the three studies, Diepeveen et $\mathrm{al}^{27}$ provided $800 \mathrm{IU} /$ day for 12 weeks $(\sim 536 \mathrm{mg})$ of $\alpha$-TP in combination with $40 \mathrm{mg} / \mathrm{day}$ of atorvastatin but failed to show any effects on plasmaoxidized LDL. On the other hand, Uzum et $\mathrm{al}^{28}$ provided $300 \mathrm{mg}$ TP/day for 20 weeks and showed decreased plasma oxidative stress markers (malondialdehyde [MDA] and erythrocyte osmotic fragility).

Despite the lack of TT studies in the ESRD population, several studies have shown beneficial effects of TT supplementation in the general population. Cardioprotective effects of TT in these studies have been primarily attributed to its antioxidative, anti-inflammatory, and lipid-lowering properties. In a study by Heng et al, ${ }^{22}$ TT supplementation in healthy volunteers resulted in lower CRP levels, which 
has been regarded as a prognostic indicator for cardiovascular events and mortality in ESRD patients..$^{29,30}$ In addition, supplementation with TT-rich fraction (TRF) from palm oil (200 mg/day for 8 weeks) plus statin in hypercholesterolemic human subjects resulted in improved lipid profiles while minimizing the side effects of statins. ${ }^{24} \mathrm{~A}$ recent study showed that palm oil-derived TRF increased plasma HDLC in the elderly following 6 months of supplementation. ${ }^{31}$ Lipid altering effects of TT were attributed to their ability to suppress and stimulate ubiquitination and degradation of HMG-CoA reductase as well as to block the processing of SREBPs as demonstrated in cell culture studies. ${ }^{32,33}$

Given that HD patients experience oxidative stress, chronic inflammation, and dyslipidemia, and that TT are potent antioxidant and anti-inflammatory agents with the potential to improve lipid profiles, we hypothesized that TT supplementation would be of benefit to HD patients by improving one or more of the above conditions. The results from this pilot study form the basis of the current report. To the best of our knowledge, this is the first study to report the role of TT in HD patients.

\section{Methods}

\section{Patients}

All patients $(n=118)$ from the Great Lake Dialysis Clinic (Detroit, MI, USA) were screened for eligibility. Patients were eligible for enrolment if they were at least 18 years of age and had been on dialysis treatment for at least 3 months prior to the study. Patients who were residents of nursing homes or receiving nutritional support (tube feeding/ intradialytic parenteral nutrition) were excluded. None of the patients in the unit were known to have AIDS or to be undergoing active treatment for cancer. All patients were undergoing dialysis with the same high-flux dialyzer membrane (Fresenius Optiflux Dialyzer, Fresenius Medical Care, Waltham, MA, USA).

\section{Study design and procedures}

The present study was approved by the Human Investigation Committees of Wayne State University and Great Lake Dialysis, LLC. Written informed consent was obtained from all patients. A total of 88 patients met the inclusion criteria, but seven patients refused to participate, leading to a final number of 81 . Based on the final number of participants, randomization was made in blocks in order to keep the sizes of the treatment groups similar, and groups were uniformly distributed by key-outcome measures. Block sizes were randomly selected to reduce the potential for selection bias.
This process was performed using the Random Allocation Software version $1.0 .{ }^{34} \mathrm{~A}$ total of 81 patients were randomly allocated into TRF $(n=41)$ and placebo $(n=40)$ groups. All clinical investigators and laboratory personnel as well as the study participants were blinded from group allocation and treatment until the end of the study.

\section{Nutritional intervention and compliance}

TRF and placebo capsules were formulated by Carotino Sdn. Bhd. (Johor, Malaysia). TRF soft gel capsules used were commercially available, each consisted of $90 \mathrm{mg}$ TT (comprising $30.18 \mathrm{mg} \alpha-, 5.30 \mathrm{mg} \beta-, 41.66 \mathrm{mg} \gamma$-, and $12.86 \mathrm{mg} \delta$-TT) and $20 \mathrm{mg} \alpha$-TP. Placebo capsules contained negligible amounts of TT $(0.12 \mathrm{mg} \alpha-, 0.06 \mathrm{mg}$ $\beta$-, and $0.06 \mathrm{mg} \gamma$-TT) and TP $(0.29 \mathrm{mg} \alpha-, 0.04 \mathrm{mg} \beta$-, and $0.11 \mathrm{mg} \gamma$-TP). All capsules contained $200 \mathrm{mg}$ wheat germ oil. Patients were provided with two TRF or placebo capsules during each dialysis session (three times a week). They were also supplied with a pill organizer that contained TRF or placebo capsules for non-dialysis days. Patients were instructed to consume two capsules during main meals (one during lunch and one during dinner). Compliance was ascertained by "directly observed treatment" 35 - which involved nurses directly observing patients taking their supplement capsules during designated days of dialysis. Supplementation adherence on the non-dialysis days was measured by pill counting as described elsewhere. ${ }^{36}$ Briefly, patients returned the pill organizer each week and received refills - the leftover soft capsules in the pill organizer were counted and recorded. Potential changes in diet pattern were ascertained by collecting 24-hour diet recalls from all subjects (at baseline and week 16) by the same registered dietitian. Energy, macro-, and micronutrient intake were analyzed using Nutritionist-Pro (First Databank, Chicago, IL, USA) based on the USDA database. Because TT were not included in the USDA database, their content was estimated based on published values. ${ }^{37-39}$

\section{Anthropometry, blood sampling and laboratory measures}

Anthropometry measurements comprised height and weight. Patients' weights were recorded to the nearest $0.1 \mathrm{~kg}$ (Tronix Flush-Mounted In-Floor Scale, Scale-Tronix, White Plains, NY, USA) after each HD session to determine estimated dry bodyweight. Height was measured to the nearest $0.1 \mathrm{~cm}$ using a Tanita Wall Mounted Height Rod (Tanita, Arlington Heights, IL, USA). Body mass index was calculated based on the Quetelet's Index. ${ }^{40}$ 
Approximately $15 \mathrm{~mL}$ of fasting (for $\sim 10$ hours) midweek predialysis blood samples were collected from existing access sites of each study participant. Blood samples were collected into two tubes (Becton Dickson, Franklin Lakes, NJ, USA) containing either EDTA (ethylenediaminetetraacetic acid, for lipid analyses) or lithium heparin (for inflammatory markers and oxidative status analyses) at baseline and weeks 8 (lipid analyses only), 12, and 16. Plasma was isolated by centrifugation at 2,800 rpm for 20 minutes at $4^{\circ} \mathrm{C}$, divided into aliquots, and immediately stored at $-80^{\circ} \mathrm{C}$ until further analysis. Serum samples for standard renal profiles (serum albumin, blood urea nitrogen, and creatinine) were analyzed using standard automated laboratory techniques by an external laboratory (Ascend Clinical Laboratory Services, Redwood City, CA, USA).

Plasma total cholesterol (TC) and TAG were determined by enzymatic reaction (Pointe Scientific Inc, Canton, MI, USA). HDLC was measured in the supernatant after precipitation of apoB-containing lipoproteins by dextran sulfate and magnesium ions (Pointe Scientific Inc, Canton, MI, USA). LDLC was calculated using the Friedwald equation by difference ( $\mathrm{LDLC}=\mathrm{TC}-\mathrm{HDLC}-\mathrm{TAG} / 5)$.

Cholesteryl ester transfer protein (CETP) activity in the plasma was assessed using a fluorometric assay kit as per the manufacturer's protocol (BioVision, Mountain View, CA, USA). Briefly, plasma samples were incubated at $37^{\circ} \mathrm{C}$ with a donor molecule containing a fluorescent self-quenched neutral lipid that is transferred to an acceptor molecule in the presence of CETP resulting in an increase in fluorescence. Fluorescent intensity was measured using a fluorometer $($ excitation $=465 \mathrm{~nm}$; emission $=535 \mathrm{~nm}$ ) (Tecan, Männedorf, Switzerland), quantified and expressed as pmoles $/ \mu \mathrm{L}$ plasma/hour.

CRP levels were measured using commercial kits based on ELISA (enzyme-linked immunoabsorbent assay) method as per the manufacturer's protocol (Cayman Chemical, Ann Arbor, MI, USA). Plasma samples were diluted in the assay buffer into $1: 15,000$, and $100 \mu \mathrm{L}$ of each sample was placed into a 96-well microplate that had been coated with a monoclonal antibody specific for human CRP, and incubated for an hour. The plate was then rinsed four times with wash buffer before addition of horseradish peroxidase-labeled CRP monoclonal antibody. Two antibodies were added and formed a sandwich by binding to different locations on the CRP molecule. CRP concentration in the plasma samples was measured at $450 \mathrm{~nm}$ after addition of chromogenic substrate tetramethylbenzidine that formed a distinct yellow color. IL-6 (Thermo Scientific, Rockford, IL, USA) and ApoA1 (Immunology Consultants
Lab, Inc, Portland, OR, USA) in the plasma were also measured using similar principles per manufacturers' protocol.

Total antioxidant power (TAP) of the plasma was measured using commercial kits based on a cupric reducing antioxidant capacity spectrophotometric method (Oxford Biomedical, Oxford, MI, USA). Briefly, $200 \mu \mathrm{L}$ of diluted plasma samples (1:40 of plasma/dilution buffer) were placed in a 96-well microplate followed by the addition of copper solution $(50 \mu \mathrm{L})$ and stop solution $(50 \mu \mathrm{L})$. The reduction potential in the plasma sample converts $\mathrm{Cu}^{2+}$ into a reduced form of copper $\left(\mathrm{Cu}^{1+}\right)$ which in turn formed a stable 2:1 complex with the chromogenic reagent. This color complex was quantified with an absorption maximum at $450 \mathrm{~nm}$. Standard curve was prepared using a known concentration of trolox, with data being expressed as $\mathrm{mM}$ trolox equivalents.

MDA in the plasma was measured indirectly based on the reaction of a chromogenic reagent, 2-thiobarbituric acid with MDA using a spectrophotometric method (Oxford Biomedical, Oxford, MI, USA). Plasma samples were deproteinized with trichloroacetic acid (Fisher Scientific, Fair Lawn, NJ, USA), and the supernatant was obtained by centrifugation. Total MDA in the deproteinized plasma samples was determined by the addition of indicator solution followed by incubation at $65^{\circ} \mathrm{C}$ for 30 minutes, and the color complex was quantified with an absorption maximum at $540 \mathrm{~nm}$. Standard curve was prepared using a known concentration of MDA stock solution supplied in the kit.

\section{Statistical analysis}

All results were analyzed using an intention-to-treat principle in which all data were counted regardless of post-randomization withdrawal, and any missing values were reported accordingly. Statistical analyses were carried out using SPSS version16 (IBM, Chicago, IL, USA). Data for categorical variables were reported as number and percentage, while continuous data were reported as mean \pm standard deviation or median \pm interquartile range (IQR) for skewed variables. Between-group difference in the change in parameters at particular time points was tested using independence $t$-test (or respective nonparametric test for non-normality distributed variables). One-way repeated measures analysis of variance (ANOVA) were used to test time effects (the change from baseline) for variables of interest in each group. $\chi^{2}$ statistic was used to evaluate differences in categorical variables. Correlations between selected variables were calculated using Pearson's correlation coefficients test. $P$-values of $<0.05$ were regarded as statistically significant. 


\section{Results}

\section{Characteristics of the study population}

A total of 81 patients were randomized into placebo $(n=40)$ and TRF $(n=41)$ groups and were provided either TRF or placebo capsules for 16 weeks. Two patients in the placebo group died due to cardiac arrest during the course of the study. An additional two patients (1 placebo; 1 TRF) were excluded due to transplantation and catheter dysfunction, respectively.

Table 1 shows the clinical and demographic characteristics of the study population. There were no significant differences in all demographic and clinical variables at baseline. Our study population was homogenously comprised of African-American ethnicity. Average body mass index for placebo $\left(28.7 \pm 8.2 \mathrm{~kg} / \mathrm{m}^{2}\right)$ and TRF $\left(30.3 \pm 8.1 \mathrm{~kg} / \mathrm{m}^{2}\right)$ groups were in the category of overweight based on the World Health Organization (2000) classification. ${ }^{41}$ Over $60 \%$ of the patients in both placebo and TRF groups had diagnosed diabetes mellitus. Moreover, ten patients (five placebo; five TRF) were positive for hepatitis $\mathrm{C}$ antibody test (RIBA Reflex Siemens

Table I Baseline clinical and demographic characteristics of the study population

\begin{tabular}{|c|c|c|c|}
\hline & $\begin{array}{l}\text { Placebo } \\
(n=40)\end{array}$ & $\begin{array}{l}\text { TRF } \\
(n=4 I)\end{array}$ & $P$-value \\
\hline \multicolumn{4}{|l|}{ Demographics } \\
\hline Age (years) & $58 \pm 13$ & $59 \pm 12$ & 0.565 \\
\hline Age $>65$ years $(n, \%)$ & $12(30)$ & $14(34)$ & 0.689 \\
\hline \multicolumn{4}{|l|}{ Ethnicity } \\
\hline African American (n, \%) & $40(100)$ & $40(97.5)$ & - \\
\hline Sex (males, \%) & $23(57.5)$ & $20(48.8)$ & 0.432 \\
\hline Smoking cigarettes (n, \%) & $10(25.0)$ & $10(24.3)$ & \\
\hline \multicolumn{4}{|l|}{ Clinical } \\
\hline Diabetes mellitus (n, \%) & $26(65)$ & $25(6 \mathrm{I})$ & 0.708 \\
\hline Hepatitis C (n, \%) & $5(12.5)$ & $5(12.2)$ & 0.967 \\
\hline Time on dialysis (months) & $37 \pm 18$ & $34 \pm 19$ & 0.446 \\
\hline BMI $\left(\mathrm{kg} / \mathrm{m}^{2}\right)$ & $28.7 \pm 8.2$ & $30.3 \pm 8.1$ & 0.768 \\
\hline Systolic BP (mmHg) & $150 \pm 24$ & $153 \pm 23$ & 0.651 \\
\hline Diastolic BP (mmHg) & $81 \pm 15$ & $83 \pm 14$ & 0.506 \\
\hline $\mathrm{Kt} / \mathrm{V}$ & $1.48 \pm 0.26$ & $1.45 \pm 0.20$ & 0.516 \\
\hline Statins (n, \%) & II (27.5) & $17(4 \mid .4)$ & 0.124 \\
\hline Aspirin (n, \%) & $22(55.0)$ & $25(61.0)$ & 0.297 \\
\hline $\begin{array}{l}\text { Anti-hypertensive, one or } \\
\text { more type }(n, \%)\end{array}$ & $35(87.5)$ & $34(82.9)$ & 0.562 \\
\hline Vascular access & & & 0.732 \\
\hline Arteriovenous fistula (n, \%) & $18(45)$ & $15(36.6)$ & \\
\hline Arteriovenous graft (n, \%) & $13(32.5)$ & $16(39)$ & \\
\hline Venous catheter (n, \%) & $9(22.5)$ & $10(24.4)$ & \\
\hline
\end{tabular}

Notes: Data are reported as mean \pm standard deviation for continuous variables and number (percentage) for categorical variables. $P$-values are comparison between groups at baseline obtained from independent $t$-test, or Pearson's $\chi^{2}$ test wherever appropriate.

Abbreviations: $\mathrm{BMI}$, body mass index; BP, blood pressure; Kt/ $\mathrm{V}$, Index of Dialysis Adequacy; TRF, tocotrienol-rich fraction.
Centaur chemiluminescent assay). Lipid-lowering drugs (statins) were used by 28 patients (eleven in placebo, 17 in TRF), aspirin were prescribed to 47 patients (22 placebo, $25 \mathrm{TRF}$ ) and 69 patients were prescribed one or more types of antihypertensive drug ( 35 placebo, $34 \mathrm{TRF}$ ). However, there were no differences in terms of drug distribution between the two groups based on $\chi^{2}$ test. In terms of dialysis parameters, both placebo and TRF groups had comparable dialysis treatment adequacy as measured by $\mathrm{Kt} / \mathrm{V}(\mathrm{K}$, dialyzer clearance of urea; $\mathrm{t}$, dialysis time; and $\mathrm{V}$, volume of distribution of urea). In terms of vascular access route, both groups had a similar proportion of patients using either an arteriovenous fistula (18 placebo, 15 TRF), an arteriovenous graft (13 placebo, 16 TRF), or venous catheter ( 9 placebo, $10 \mathrm{TRF}$ ).

\section{Dietary intake, tolerability, side effects and compliance}

Dietary analysis based on 24-hour dietary recall during baseline and week 16 of the study showed that there were no changes in energy and macronutrients between the two groups at a given particular time point. There were no differences in vitamin E (TP and TT) intake at baseline and week 16. Similar results were also seen in vitamin $C, \beta$-carotene, and other micronutrient (potassium, phosphorus) intake within and between the groups (Table S1). Meanwhile, a total of $62 \%$ of our study population ( $58 \%$ placebo [ $n=23]$ and $66 \%$ TRF [n=27]) were taking dietary supplements that comprised Renalcaps (18\% placebo, 18\% TRF), Nephrocaps ( $3 \%$ placebo, $3 \% \mathrm{TRF}$ ), vitamin C ( $0 \%$ placebo, $2 \% \mathrm{TRF}$ ), and multivitamins ( $2 \%$ placebo, $2 \%$ TRF). Nephrocaps and Renalcaps comprised $100 \mathrm{mg}$ vitamin C, $1.5 \mathrm{mg}$ thiamine, $1.7 \mathrm{mg}$ riboflavin, $20 \mathrm{mg}$ niacin, $10 \mathrm{mg}$ vitamin $\mathrm{B} 6,1 \mathrm{mg}$ folate, $6 \mu \mathrm{g}$ vitamin B12, $150 \mu \mathrm{g}$ biotin, and $5 \mathrm{mg}$ pantothenic acid.

TRF and placebo supplements were well tolerated by the subjects. During the first week of the study, one patient from the placebo group reported diarrhea, but this was not related to supplementation, and subsequently resumed the study. No other adverse effects were reported from subjects in either group to justify removal from the study. In the current study, compliance was ascertained by direct and real-time observation of subjects taking the supplements during dialysis sessions (three times a week) as well as a pill counting method on non-dialysis days. Compliance during non-dialysis days was more than $70 \%$ for each week except during week 14 and week 15 due to holidays (Thanksgiving). There were no differences in capsule consumption (percentage of capsule disappearance) between placebo and TRF groups during the course of the study (Figure S1). Compliance of supplementation at home 
was relatively good considering that the study population was comprised of low income and low literacy subjects, who typically are associated with poor compliance..$^{35,42}$

\section{Effects on nutritional, inflammatory and oxidative markers}

Nutritional, inflammatory, and oxidative indices are presented in Table 2. Data for CRP and IL-6 are reported as median $\pm I Q R$ because they were skewed. Median CRP levels at baseline were

Table 2 Inflammatory, oxidative, and nutritional markers during baseline, week 12, and week 16

\begin{tabular}{|c|c|c|}
\hline & $\begin{array}{l}\text { Placebo } \\
(n=38)\end{array}$ & $\begin{array}{l}\text { TRF } \\
(n=40)\end{array}$ \\
\hline \multicolumn{3}{|c|}{ Inflammatory markers } \\
\hline \multicolumn{3}{|c|}{$\mathrm{CRP}(\mathrm{mg} / \mathrm{L})$} \\
\hline Baseline & $16.6 \pm 28.8$ & $13.0 \pm 20.5$ \\
\hline Week 12 & $25.1 \pm 36.5$ & $15.5 \pm 18.0$ \\
\hline Week 16 & $17.9 \pm 39.5$ & $14.3 \pm 28.0$ \\
\hline \multicolumn{3}{|l|}{ IL-6 (pg/mL) } \\
\hline Baseline & $4.6 \pm 5.9$ & $4.9 \pm 3.5$ \\
\hline Week 12 & $5.2 \pm 3.5$ & $4.9 \pm 2.3$ \\
\hline Week 16 & $5.2 \pm 2.1$ & $5.9 \pm 3.1$ \\
\hline \multicolumn{3}{|c|}{ Oxidative status } \\
\hline \multicolumn{3}{|c|}{ TAP (mM Trolox equivalent) } \\
\hline Baseline & $640 \pm 207$ & $669 \pm 127$ \\
\hline Week 12 & $564 \pm 95^{a}$ & $626 \pm 98^{a}$ \\
\hline Week 16 & $697 \pm 166$ & $759 \pm 246$ \\
\hline \multicolumn{3}{|c|}{ TBARS ( $\mu$ M MDA) } \\
\hline Baseline & $3.39 \pm 5.12$ & $3.01 \pm 4.65$ \\
\hline Week 12 & $4.68 \pm 5.72$ & $2.60 \pm 2.28$ \\
\hline Week 16 & $3.85 \pm 3.90$ & $2.89 \pm 3.65$ \\
\hline \multicolumn{3}{|c|}{ Nutritional indicators } \\
\hline \multicolumn{3}{|c|}{ Serum Alb (g/dL) } \\
\hline Baseline & $3.9 \pm 0.3$ & $3.9 \pm 0.3$ \\
\hline Week 12 & $3.9 \pm 0.3$ & $3.9 \pm 0.3$ \\
\hline Week 16 & $4.0 \pm 0.4$ & $3.9 \pm 0.5$ \\
\hline \multicolumn{3}{|l|}{$\mathrm{Hb}(\mathrm{g} / \mathrm{L})$} \\
\hline Baseline & $10 \pm 2$ & $10 \pm 2$ \\
\hline Week 12 & $10 \pm 1$ & $10 \pm 2$ \\
\hline Week 16 & $10 \pm 1$ & $10 \pm 2$ \\
\hline \multicolumn{3}{|l|}{ BMI $\left(\mathrm{kg} / \mathrm{m}^{2}\right)$} \\
\hline Baseline & $28.7 \pm 8.2$ & $30.3 \pm 8.1$ \\
\hline Week 12 & $29.1 \pm 8.1$ & $30.4 \pm 8.2$ \\
\hline Week 16 & $29.1 \pm 8.3$ & $30.5 \pm 8.2$ \\
\hline
\end{tabular}

Notes: Values are reported as median \pm interquartile range (CRP and IL-6) or mean \pm standard deviation (TAP, TBARS, Alb, Hb, and BMI). Statistical analyses were conducted using one-way repeated measures analysis of variance to test the difference in the parameters over time compared with the baseline in each group - no significant difference was observed. Independent $t$-test (TAP,TBARS, Alb, $\mathrm{Hb}$, and $\mathrm{BMI}$ ) and Mann-Whitney $U$ test (CRP and IL-6) were used to test the mean differences between TRF and placebo groups at particular time points. adenotes significant difference $(P<0.05)$ for these tests. At week 12 , there was marginal difference $(P=0.055)$ in TBARS ( $\mu$ M MDA) between placebo and TRF groups.

Abbreviations: Alb, albumin; BMI, body mass index; CRP, C-reactive protein; $\mathrm{Hb}$, hemoglobin; IL-6, interleukin-6; MDA, malondialdehyde; TAP, total antioxidant power;TBARS, thiobarbituric acid reactive substances; TRF, tocotrienol-rich fraction.
$16.6 \pm 28.8$ and $13.0 \pm 20.5 \mathrm{mg} / \mathrm{L}$ for the placebo and TRF group, respectively. There was no difference in CRP levels between TRF and placebo at each time point. No significant changes were noted in the CRP levels in both groups per repeated measures one-way ANOVA. Similarly, there was no difference in mean IL-6 between or within groups at all time points.

Measurement of TAP showed that the TRF group had significantly higherTAP $(P<0.05)$ at week 12 compared with placebo (626 \pm 98 versus $564 \pm 95 \mathrm{mMTrolox}$ equivalent). However, no changes were observed within the TRF and placebo groups when compared with baseline. This was also in concert with indirect measurement of MDA, a marker for oxidative stress, in which the TRF group had a lower MDA $(2.60 \pm 2.28 \mu \mathrm{M}$ MDA $)$ at week 12 compared with the placebo group $(4.68 \pm 5.72 \mu \mathrm{M}$ MDA) $(P=0.055)$. There were no significant changes in MDA values within the TRF and placebo groups. In terms of nutritional indicators (serum albumin, hemoglobin, and body mass index), no changes were observed within or between groups.

\section{Effects on lipid profiles}

Plasma TAG levels were significantly reduced in the TRF group after 12 weeks of supplementation compared with baseline values ( $144 \pm 91$ versus $113 \pm 47 \mathrm{mg} / \mathrm{dL}$ plasma, $P<0.05$ ) and remained significantly reduced at week $16(144 \pm 91$ versus $103 \pm 45 \mathrm{mg} / \mathrm{dL}$ plasma, $P<0.05$ ). In contrast, TAG levels remained the same in the placebo group. Interestingly, both groups showed a progressive decline in plasma TC and a significant improvement in HDLC when compared with the baseline values starting at week 8 . Hence, this also resulted in a reduction of LDLC and the ratio of TC/HDLC (Table 3).

As TAG levels were somewhat higher in the TRF group at baseline, values were normalized to these baseline values. Normalized plasma TAG were reduced in the TRF group compared with placebo at week $12(-33 \pm 84$ versus $6 \pm 66 \mathrm{mg} / \mathrm{dL}$, $P=0.032)$, and at week $16(-36 \pm 79$ versus $-8 \pm 47 \mathrm{mg} / \mathrm{dL}$, $P=0.072$ ) (Figure 1). Plasma HDLC was significantly higher in the TRF group compared with placebo at both week $12(22 \pm 15$ versus $9 \pm 11 \mathrm{mg} / \mathrm{dL}, P<0.0001)$ and week $16(16 \pm 14$ versus $10 \pm 9 \mathrm{mg} / \mathrm{dL}, P<0.05$, respectively) (Figure 2).

Measurement of ApoA1 concentration in the plasma, a major protein component of HDL particles, revealed that it was significantly higher in the TRF group compared with placebo at week $12(1.56 \pm 0.59$ versus $1.27 \pm 0.34 \mathrm{mg} / \mathrm{mL}$, $P<0.05$, respectively) (Figure $3 \mathrm{~A}$ ), consistent with the higher HDLC concentrations. However, no difference was noted between groups at week 16 .

Measurement of CETP activity, a plasma protein that facilitates the transfer of cholesteryl ester from HDL in 
Table 3 Lipid profiles of the subjects at baseline, week 8, week 12 , and week 16

\begin{tabular}{|c|c|c|}
\hline & $\begin{array}{l}\text { Placebo } \\
(n=38)\end{array}$ & $\begin{array}{l}\text { TRF } \\
(n=40)\end{array}$ \\
\hline \multicolumn{3}{|c|}{ TAG (mg/dL) } \\
\hline Baseline & $109 \pm 63$ & $|44 \pm 9|$ \\
\hline Week 8 & $|06 \pm 5|$ & $139 \pm 86$ \\
\hline Week 12 & $100 \pm 57$ & $113 \pm 47^{\mathrm{a}}$ \\
\hline Week 16 & $95 \pm 48$ & $103 \pm 45^{a}$ \\
\hline \multicolumn{3}{|l|}{ TC (mg/dL) } \\
\hline Baseline & $179 \pm 42$ & $183 \pm 49$ \\
\hline Week 8 & $153 \pm 32^{\mathrm{a}}$ & $158 \pm 36^{a}$ \\
\hline Week 12 & $|40 \pm 3|^{a}$ & $142 \pm 43^{a}$ \\
\hline Week 16 & $149 \pm 38^{a}$ & $145 \pm 45^{a}$ \\
\hline \multicolumn{3}{|c|}{ HDLC (mg/dL) } \\
\hline Baseline & $44 \pm 12$ & $42 \pm 13$ \\
\hline Week 8 & $51 \pm 14^{a}$ & $5 I \pm 15^{a}$ \\
\hline Week 12 & $54 \pm \mid 3^{\mathrm{a}, \mathrm{b}}$ & $63 \pm 18^{a, b}$ \\
\hline Week 16 & $54 \pm 12^{\mathrm{a}}$ & $58 \pm 18^{a}$ \\
\hline \multicolumn{3}{|c|}{ LDLC (mg/dL) } \\
\hline Baseline & $112 \pm 38$ & $112 \pm 46$ \\
\hline Week 8 & $8 I \pm 3 I^{a}$ & $79 \pm 35^{a}$ \\
\hline Week 12 & $70 \pm 32^{\mathrm{a}}$ & $58 \pm 38^{a}$ \\
\hline Week 16 & $75 \pm 34^{a}$ & $66 \pm 42^{a}$ \\
\hline \multicolumn{3}{|c|}{ TC/HDLC ratio } \\
\hline Baseline & $4.25 \pm 1.36$ & $4.59 \pm 1.80$ \\
\hline Week 8 & $3.19 \pm 1.08$ & $3.29 \pm 1.07$ \\
\hline Week 12 & $2.80 \pm 1.13$ & $2.38 \pm 0.87$ \\
\hline Week 16 & $2.88 \pm 1.07$ & $2.66 \pm 1.03$ \\
\hline
\end{tabular}

Notes: Values are reported as mean \pm standard deviation. TAG, TC, and HDLC were measured using standard enzymatic assay, whilst LDLC was calculated using the Friedewald equation. One-way repeated measures analysis of variance was used to test the difference in the parameters over time compared with the baseline in each group. adenotes significant difference $(P<0.05)$ for this test. Independent $t$-test was used to test the mean differences between TRF and placebo groups at particular time points. 'benotes significant difference $(P<0.05)$ for these tests.

Abbreviations: HDLC, high-density lipoprotein cholesterol; LDLC, low-density lipoprotein cholesterol; TAG, triacylglycerol; TC, total cholesterol; TRF, tocotrienolrich fraction.

exchange for TAGs from TAG-rich lipoprotein, was significantly lower in the TRF group at week 16 compared with placebo ( $96 \pm 18$ versus $129 \pm 43 \mathrm{pmol} / \mathrm{mL}$ plasma/hour, $P<0.001$, respectively), which reflected the higher HDLC value in the TRF group. Interestingly, CETP activity was slightly higher in the TRF group during week $12(95 \pm 19$ versus $84 \pm 19 \mathrm{pmol} / \mathrm{mL}$ plasma/hour, $P<0.05$, respectively) (Figure 3B). Pearson's correlation test between HDLC levels and ApoA1 concentration during week 12 and week 16 showed a significant correlation between the two variables. Similarly, significant correlations were observed between plasma TAG and CETP (Figure 4).

\section{Discussion}

The present study, to the best of our knowledge, is the first to report the extent of vitamin E TRF supplementation effects on inflammatory markers, oxidative status, and lipid profiles in HD subjects. This study highlights some important findings, especially in the lipid-altering properties of TT, which could potentially have clinical implications. Patients in both the placebo and TRF groups had comparable demographics, percentage of smoking cigarettes, dialysis, and clinical parameter distributions. In addition, baseline inflammatory markers, oxidative status, and lipid profiles in both groups were not statistically different. Thus, any potential comorbidities and confounding factors were minimized by being randomly distributed across the two groups.

In this study, we observed that baseline median CRP levels in both groups were relatively higher compared with commonly reported values in the literature ${ }^{43,44}$ However, this is in accordance with our previous results, ${ }^{35}$ despite methodological differences between the two studies. The fact that gradual increments in CRP levels were seen in both groups might suggest a progressive inflammatory burden in this population. Results from the present study indicated that short-term TRF administration was unable to improve CRP levels in HD patients. This is in contrast with a recent TRF trial that has been conducted in healthy volunteers which showed reduction in CRP levels in older subjects. ${ }^{22}$ We speculate that this is partially due to high inter-individual variability in CRP levels, which is often associated with transient intercurrent clinical events and the dynamic response of immune system. ${ }^{45}$ Despite the high predictive power of mortality in a single CRP measurement, ${ }^{46}$ given the fact that CRP fluctuates dramatically upon acute inflammation ${ }^{47}$ or even in the absence of changes in other biochemical measures or health status, ${ }^{47-49}$ CRP measurement alone may not adequately capture immunomodulatory changes following therapeutic intervention, thus necessitating measurement of other inflammatory biomarkers. Similar observations were also seen in IL-6 values. In terms of oxidative status parameters, no significant improvements were seen in TAP and MDA values in either the TRF or the placebo group over time, but the TRF group had higher TAP and marginally lower MDA at week 12 , which was not seen at week 16 . Taken together, TRF supplementation failed to improve inflammatory and oxidative status markers in the current study.

Interestingly, TRF supplementation resulted in improvement in plasma TAG and HDLC. The improvement in lipid profiles was less anticipated due to mixed results in previous human trials. For example, Mustad et a ${ }^{50}$ administered $200 \mathrm{mg}$ TT/day for 28 days in healthy hypercholestrolemic volunteers but failed to show any effects on blood lipids. Similarly, supplementation with a TT-rich vitamin E 


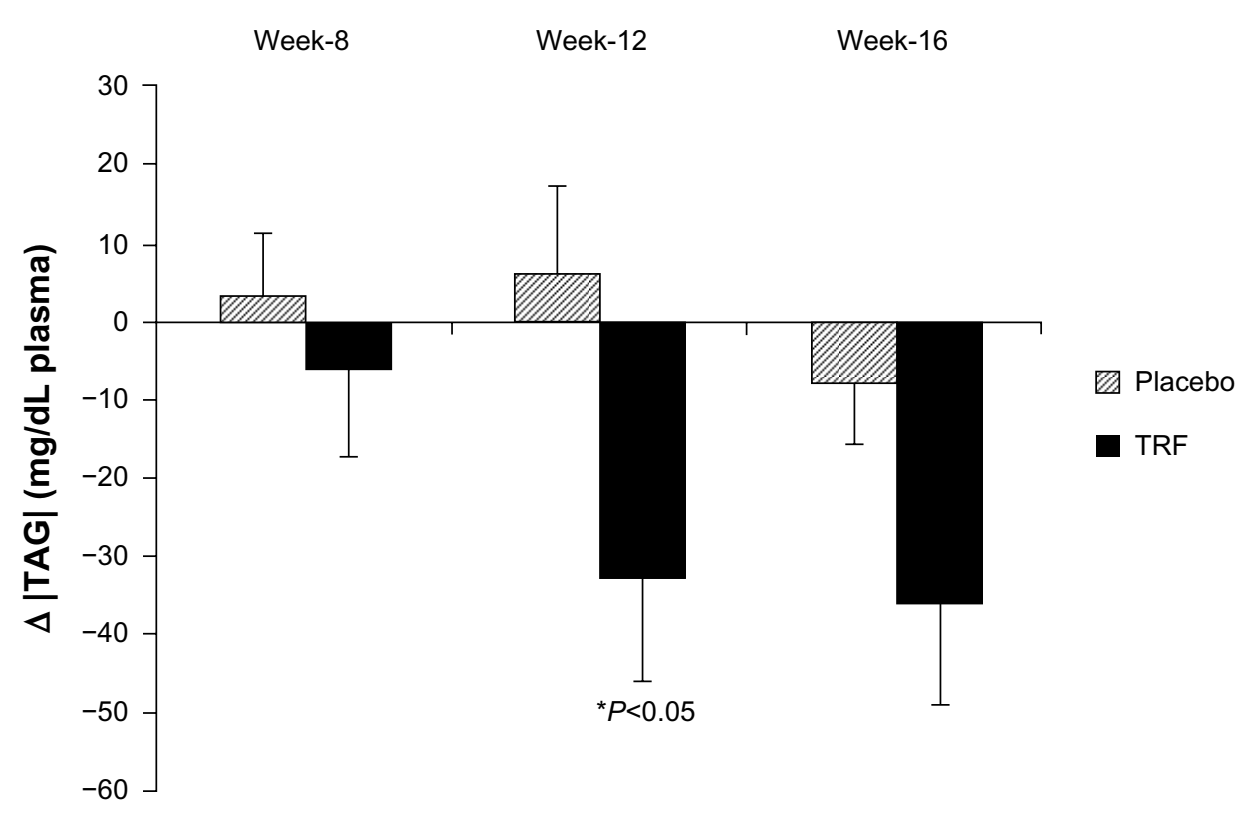

Figure I Mean changes in plasma TAG normalized to baseline.

Notes: Values are presented as mean \pm standard error of the mean. TAG data were normalized using baseline values. *Significant difference $(P<0.05)$ compared with placebo at each time point based on independent $t$-test. At week 16, there was a marginal difference between TRF and placebo groups $(P=0.072)$.

Abbreviations: TAG, triacylglycerols; TRF, tocotrienol-rich fraction.

concentrate (140 mg TT, $80 \mathrm{mg}$ TP per day) to 20 men for 42 days showed no improvement in lipoprotein profiles despite changes in plasma TP and TT concentrations. ${ }^{51} \mathrm{We}$ speculate that the earlier studies in human volunteers did not show a positive result in blood lipids due to a shorter duration, a smaller dose, and smaller sample size. A recent study which administered TT for a longer period (6 months) in healthy older adults showed significant improvement in lipid profiles (increased HDLC and improved TC/HDLC ratios), ${ }^{31}$ which strengthen the speculation that TT effects on blood lipids could be a function of time and may depend on a subject's clinical status.

Because dyslipidemia is implicated in the pathogenesis of cardiovascular diseases, it has become more common

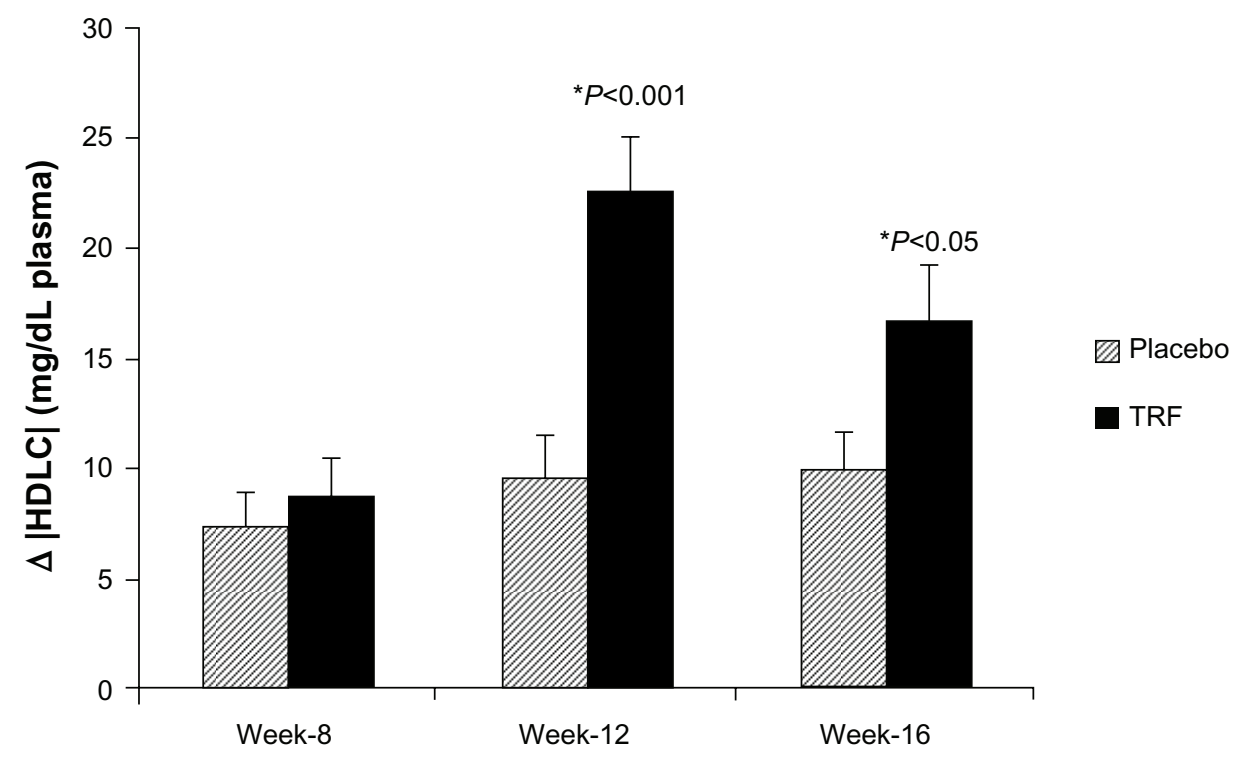

Figure 2 Mean changes in plasma HDLC normalized to baseline.

Notes: Values are presented as mean \pm standard error of the mean. HDLC data were normalized using baseline values. *Significant difference $(P<0.05)$ compared with placebo at each time point based on independent $t$-test.

Abbreviations: HDLC, high-density lipoprotein cholesterol; TRF, tocotrienol-rich fraction. 


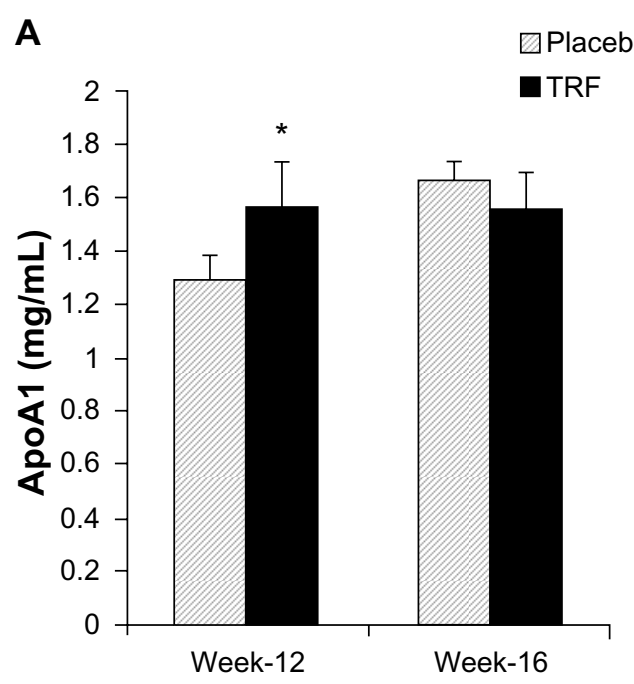

B

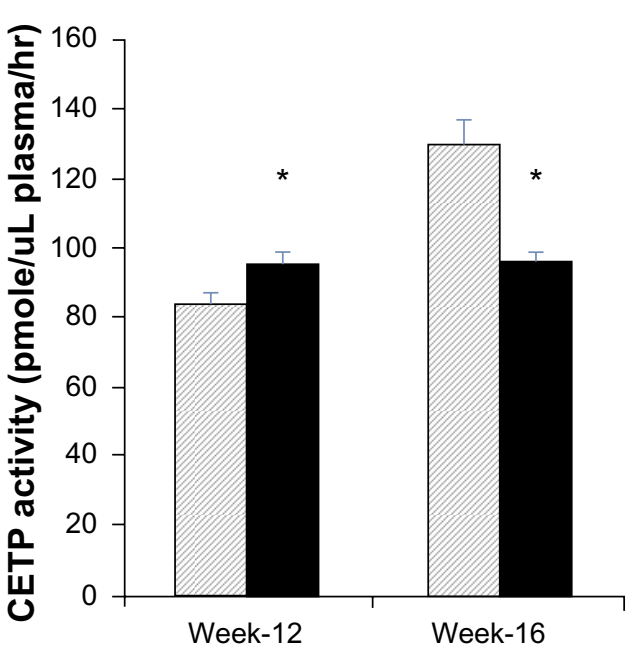

Figure 3 Comparison of ApoAI (A) and CETP activity (B) during week 12 and week 16.

Notes: Data are presented as mean \pm standard error of the mean. *Significant difference $(P<0.05)$ compared with placebo at each time point, tested by independent $t$-test. Figure (A) shows plasma ApoAI concentration during week 12 and week 16 in both groups as measured by ELISA method. Figure (B) shows CETP activity during week 12 and week 16 in both groups as measured in the plasma using fluorometric assay kit.

Abbreviations: ApoAI, apolipoprotein AI; CETP, cholesteryl ester transfer protein; ELISA, enzyme-linked immunoabsorbent assay; TRF, tocotrienol-rich fraction.

for dialysis patients with dyslipidemia to receive statin treatment, ${ }^{52}$ albeit with conflicting evidence. ${ }^{53}$ In our study population, eleven patients in the placebo group and 17 patients in the TRF group were on statin treatment. Statin-induced inhibition of HMG CoA reductase leads to depletion of hepatic cholesterol pools and subsequently decreases production of apoB-containing VLDL particles and upregulates LDL receptors. Because VLDLs are the major TAG-trafficking lipoprotein in fasting plasma, statins reduce TAG by enhancing clearance of VLDL and reuptake of LDL via LDL receptors. In the present study, TAG levels were significantly reduced in TRF groups at week 12 but not at week $16(P=0.07)$, partly due to high variability in both groups. We postulated that this variability may partly be due to statin users in the placebo group. Additional analysis among statin users revealed that the TAG reduction observed in the placebo group was indeed due to statin administration (Figure S2). Interestingly, in the TRF group, both the statin and non-statin users showed a reduction trend in TAG, which strengthens the speculation that TRF may be directly involved in the TAG reduction process. Similar findings have been shown in a randomized, placebo-controlled clinical trial by Zaiden et al, ${ }^{54}$ in which supplementation with $120 \mathrm{mg}$ of $\gamma$ -,$\delta$-tocotrienols $(\gamma-, \delta$-T3) for 8 weeks resulted in a $\sim 28 \%$ reduction in TAG compared with baseline. This improvement in TAG was partly explained by suppression of the upstream regulators of lipid homeostasis, as demonstrated in an in-vitro study. ${ }^{54}$
The increase in HDLC levels in the plasma can be attributed in part to increased production of HDL particles, delayed catabolism of HDL particles, or higher cholesterol content in HDL particles. To elucidate the mechanism of TT effects on TAG and HDLC during week 12 and week 16, ApoA1 and CETP were measured. Our results showed that the ApoA1 level was significantly higher in the TRF group during week 12 , which coincided with higher HDLC in the TRF group. Because ApoA1 is the major protein component of HDL particles (70\%), increased HDLC levels at week 12 in the TRF group may be explained by an increase in HDL particles (mirrored by higher ApoA1 concentration). Pearson's correlation test between HDLC levels and ApoA1 concentration during week 12 and week 16 confirmed significant correlation between the two variables.

Animal studies have established that about one-third of ApoA1 is catabolized by the kidney and the rest by the liver - humans are assumed to have similar pathway of ApoA1 catabolism. ${ }^{55,56}$ In the context of ESRD patients, because kidney functions are impaired, this also hypothetically leads to reduction of ApoA1 catabolism. Conversely, a recent study showed that ESRD patients on HD have higher prevalence of autoantibodies to ApoA1 (anti-ApoA1 IgG) which correlates with dialysis vintage. ${ }^{57}$ Similarly, in a comparative study between healthy control and HD patients, Pahl et al ${ }^{58}$ found that plasma HDLC is markedly reduced in HD patients, which was mirrored by reduced ApoA1 plasma concentration. Taken together, 
A
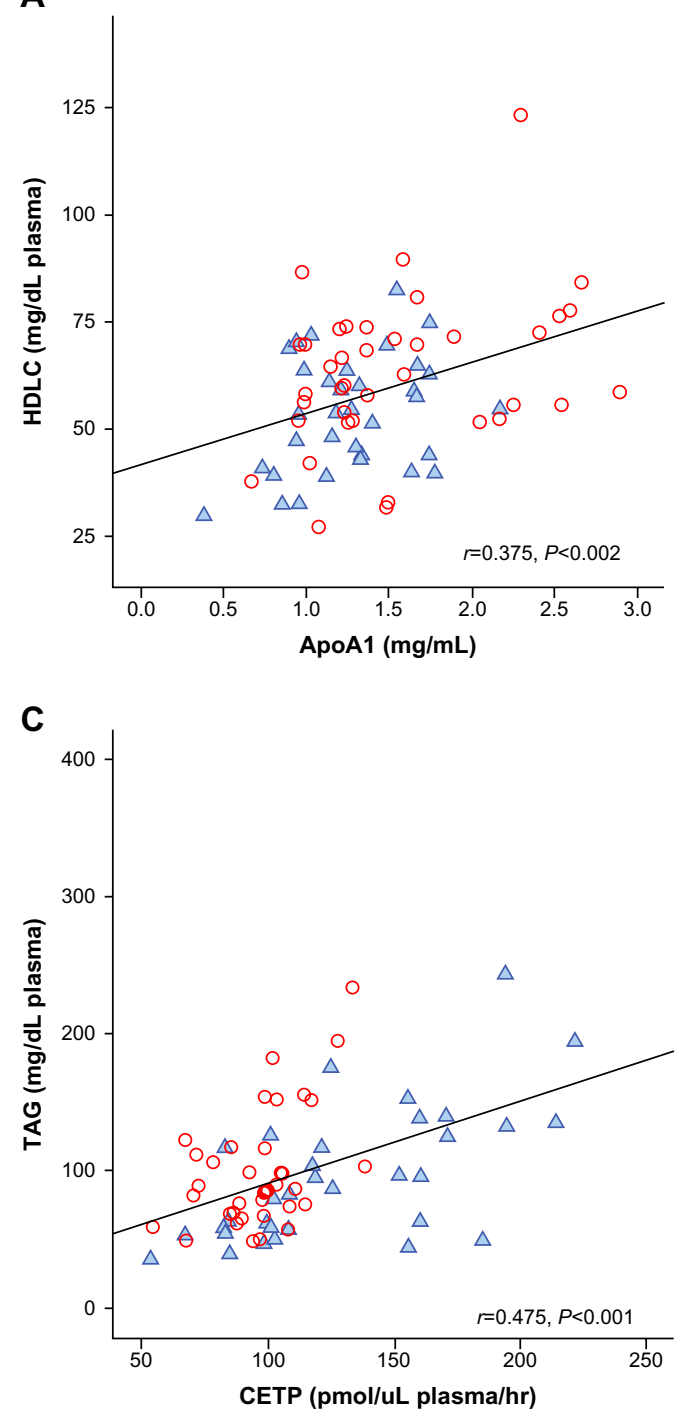

B

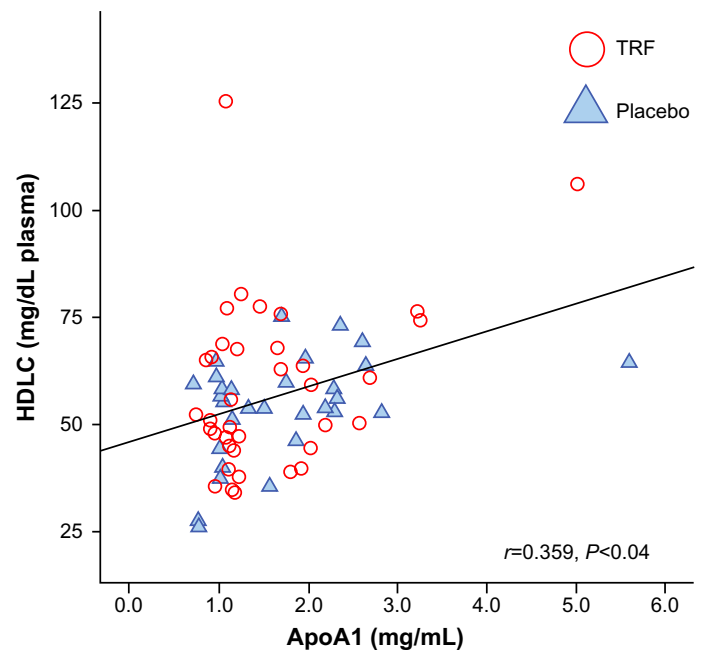

D

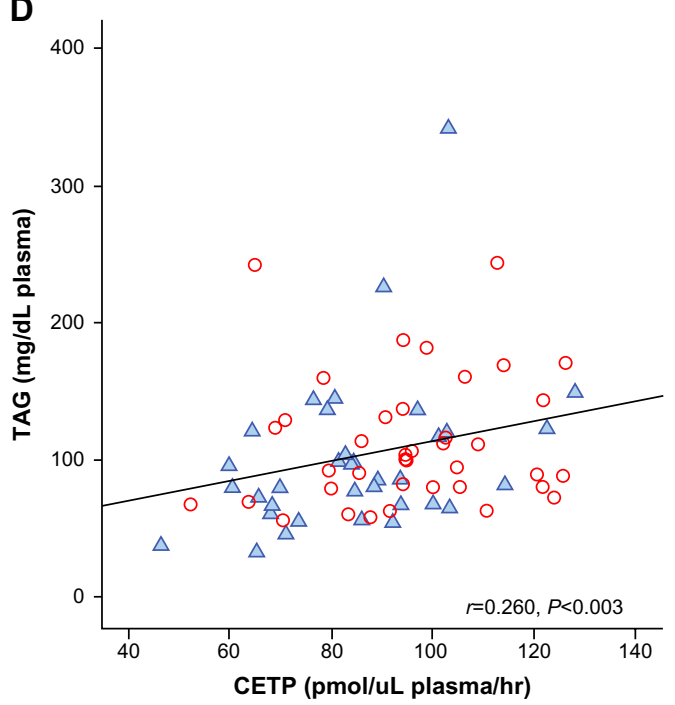

Figure 4 Pearson's correlation coefficient in lipid parameters during week 12 and week 16.

Notes: (A and B) Correlation between ApoAI (mg/mL plasma) and HDLC (mg/dL plasma) at week 12 and week I6, respectively. (C and D) Correlation between CETP activity (pmol/ $\mu \mathrm{L}$ plasma/hour) and TAG (mg/dL plasma) at week 12 and week 16 , respectively.

Abbreviations: ApoAI, apolipoprotein AI; CETP, cholesteryl ester transfer protein; HDLC, high-density lipoprotein cholesterol; TAG, triacylglycerols; TRF, tocotrienolrich fraction.

these may partially explain low HDLC observed in ESRD/ HD patients.

In the context of our study, the TRF supplemented group had significant increase in HDLC which was reflected by higher plasma ApoA1 concentration. In concert with the current study, Heng et $\mathrm{al}^{22}$ demonstrated that supplementation with $150 \mathrm{mg}$ /day TRF in a healthy population resulted in increased expression of ApoA1 precursor. The effect on ApoA1 may not be unique to TT per se because $\alpha$-TP supplementation also increased pro-apoA 1 and apoA1 concentration. ${ }^{59}$ Literature on molecular explanation of TRF effects on ApoA1 expression is scarce, thus further investigation in this area is warranted. It is possible that TRF and TP exhibit antioxidant-like mechanisms which implicate several transcription factors such as MAP, PPAR $\alpha$, and PPAR $\gamma$ in the upregulation of pro-apoA $1 .{ }^{59}$

CETP activity was lower in the TRF group during week 16 , consistent with the higher HDLC value. CETP mediates the transfer of cholesterol ester from HDL to VLDL remnants in exchange for TAGs. ${ }^{15}$ Because HD patients usually experience delayed catabolism of TAG-rich lipoprotein, we speculate that CETP activity may be increased to facilitate TAG-cholesterol transfer between HDL and apoB100 lipoproteins. A recent study that compared HDL-associated 
enzymes in HD versus healthy control subjects confirmed that HD patients have higher CETP compared with control, ${ }^{60}$ while another study reported no changes in CETP. ${ }^{15}$ In our study, Pearson's correlation test between CETP activity and TAG concentration during week 12 and week 16 confirmed significant correlation between the two variables.

HD patients are frequently hospitalized due to concurrent comorbidities. In the current study, we monitored missed dialysis sessions for each patient, and the primary reason was recorded. Cumulative numbers of missed dialysis sessions for each group were calculated (Figure S3). The total number of days of hospitalization was 122 versus 180 days for the TRF and placebo groups, respectively. This is an intriguing observation. It should be noted that in a recent study in end-stage liver disease patients, ${ }^{61}$ Patel et al reported that supplementation with $400 \mathrm{mg}$ TT/day in these patients slowed the rise in Model for End-Stage Liver Disease (MELD) scores (a standardized scoring system that is clinically used to determine severity of liver failure and priority for transplantation) in $50 \%$ of the patients receiving TT supplementation. ${ }^{61}$ Coupled with our initial observation, it is possible that TT therapeutics may provide benefit due to their ability to penetrate vital organ tissues. However, this hypothesis is purely speculative at present and warrants further investigation in a larger cohort.

It is important to emphasize that the comparisons here are made to the studies that either used $\alpha$-TP in HD patients or studies that used TT/TRF in healthy volunteers of different clinical populations. Given that TT possess the distinct functions from TP in the context of their antioxidant and anti-inflammatory properties, there are no comparable visa-vis studies in HD patients.

\section{Limitations of the study}

The present study highlights beneficial treatment effects of TRF on lipids. Nevertheless, the results of this study should be interpreted with caution. Firstly, the study was homogenously comprised of a single race, and the majority of the patients were in low-income, low-literacy group. Therefore, the positive outcome of TRF on lipids may not be generalizable to a more diverse HD population. Secondly, compliance may have been a factor. However, our study design enabled us to directly monitor and observe each patient taking their supplement during regular dialysis days, while we were able to estimate consumption on non-dialysis days by the pill counting method. Dietary changes were monitored by a single 24-hour dietary recall at baseline and at the end of the study. We acknowledge the limitation of this method to adequately capture dietary changes; however, given the fact that diet monotony of dialysis patients plus limited contribution of TT-rich food sources to our patients' diet, we believe that variation in dietary contribution of TT is clinically less important in contributing to the outcome of the present study. Finally, the number of subjects in our cohort did not allow us to separate the effects of the various medication regimens (eg, statins, anti-hypertensive drugs, and aspirin) from the effects of TT per se.

We did not measure TT in the blood, as the focus of the study was to observe the global effects following oral supplementation, and not to look at the pharmacokinetics of TT supplementation per se. It is known that TT are transported in circulating lipoproteins, ${ }^{62-64}$ albeit with a short half-life, ${ }^{65}$ but recent data show that they are indeed delivered to vital organs. ${ }^{61}$ Correlating plasma TT following supplementation in HD patients will be of importance in the future as doseescalation studies are contemplated to ascertain the optimal dose of TT required in this population.

\section{Author contributions}

ZAMD was involved in the study's design, data acquisition, analysis, interpretation, and preparation of the manuscript. BT contributed to study design, monitoring, and supervision during data acquisition and review of the manuscript. MS, $\mathrm{RO}, \mathrm{JA}$, and ST shared equal contribution in data collection, supervision of the subjects, and review of the manuscript. PK was instrumental in the study's design, monitoring data acquisition and providing critical comments during manuscript preparation. All authors took part in drafting the article or revising it critically for important intellectual content.

\section{Acknowledgments}

The authors thank Dr James Sondheimer, MD, for his critical review of the manuscript. The authors are also especially thankful to Rami Hanna, Rajeev Shahani, Eno Latifi, and Aisha Chaudri for technical assistance, and the Great Lake Dialysis Clinic nurses and laboratory technician, Charles Vaughn, for their help and cooperation. The authors thank Dr Kalyana Sundram, Deputy CEO of MPOC for input into TT dosages.

\section{Disclosure}

The current work was supported in part by a grant from Malaysian Palm Oil Council. TRF and placebo capsules were 
formulated and donated by Carotino (Malaysia) Sdn. Bhd. ZAMD was supported by the Malaysian Ministry of Higher Education and Universiti Putra Malaysia. The authors declare no other conflicts of interest.

\section{References}

1. Collins AJ, Foley RN, Herzog C, et al. Excerpts from the US Renal Data System 2009 Annual Data Report. Am J Kidney Dis. 2010; 55(1 Suppl 1):S1-S420, A6-A7.

2. Collins AJ. Cardiovascular mortality in end-stage renal disease. Am J Med Sci. 2003;325(4):163-167.

3. Schiffrin EL, Lipman ML, Mann JF. Chronic kidney disease: effects on the cardiovascular system. Circulation. 2007;116(1):85-97.

4. Carrero JJ, Stenvinkel P, Cuppari L, et al. Etiology of the protein-energy wasting syndrome in chronic kidney disease: a consensus statement from the International Society of Renal Nutrition and Metabolism (ISRNM). J Ren Nutr. 2013;23(2):77-90.

5. Himmelfarb J, Stenvinkel P, Ikizler TA, Hakim RM. The elephant in uremia: oxidant stress as a unifying concept of cardiovascular disease in uremia. Kidney Int. 2002;62(5):1524-1538.

6. Vaziri ND. Causes of dysregulation of lipid metabolism in chronic renal failure. Semin Dial. 2009;22(6):644-651.

7. Kalantar-Zadeh K, Ikizler TA, Block G, Avram MM, Kopple JD. Malnutrition-inflammation complex syndrome in dialysis patients: causes and consequences. Am J Kidney Dis. 2003;42(5):864-881.

8. Galli F, Floridi AG, Floridi A, Buoncristiani U. Accumulation of vitamin E metabolites in the blood of renal failure patients. Clin Nutr. 2004;23(2):205-212.

9. Riccioni G, N DO, Scotti L, et al. Circulating plasma antioxidants, inflammatory markers and asymptomatic carotid atherosclerosis in endstage renal disease patients: a case control study. Int J Immunopathol Pharmacol. 2010;23(1):327-334.

10. Espe KM, Raila J, Henze A, et al. Low plasma alpha-tocopherol concentrations and adverse clinical outcomes in diabetic hemodialysis patients. Clin J Am Soc Nephrol. 2013;8(3):452-458.

11. Vaziri ND. Dyslipidemia of chronic renal failure: the nature, mechanisms, and potential consequences. Am J Physiol Renal Physiol. 2006;290(2):F262-F272.

12. Pennell P, Leclercq B, Delahunty MI, Walters BA. The utility of nonHDL in managing dyslipidemia of stage 5 chronic kidney disease. Clin Nephrol. 2006;66(5):336-347.

13. Vaziri ND, Liang K, Parks JS. Down-regulation of hepatic lecithin: cholesterol acyltransferase gene expression in chronic renal failure. Kidney Int. 2001;59(6):2192-2196.

14. Moradi H, Pahl MV, Elahimehr R, Vaziri ND. Impaired antioxidant activity of high-density lipoprotein in chronic kidney disease. Transl Res. 2009;153(2):77-85.

15. Vaziri ND, Navab M, Fogelman AM. HDL metabolism and activity in chronic kidney disease. Nat Rev Nephrol. 2010;6(5):287-296.

16. Jiang Q, Christen S, Shigenaga MK, Ames BN. Gamma-tocopherol, the major form of vitamin $\mathrm{E}$ in the US diet, deserves more attention. Am J Clin Nutr. 2001;74(6):714-722.

17. Serbinova E, Kagan V, Han D, Packer L. Free radical recycling and intramembrane mobility in the antioxidant properties of alphatocopherol and alpha-tocotrienol. Free Radic Biol Med. 1991;10(5): 263-275.

18. Suzuki YJ, Tsuchiya M, Wassall SR, et al. Structural and dynamic membrane properties of alpha-tocopherol and alpha-tocotrienol: implication to the molecular mechanism of their antioxidant potency. Biochemistry. 1993;32(40): 10692-10699.

19. Frank J, Chin XW, Schrader C, Eckert GP, Rimbach G. Do tocotrienols have potential as neuroprotective dietary factors? Ageing Res Rev. 2012;11(1):163-180.
20. Azlina MF, Nafeeza MI, Khalid BA. A comparison between tocopherol and tocotrienol effects on gastric parameters in rats exposed to stress. Asia Pac J Clin Nutr. 2005;14(4):358-365.

21. Wu SJ, Liu PL, Ng LT. Tocotrienol-rich fraction of palm oil exhibits anti-inflammatory property by suppressing the expression of inflammatory mediators in human monocytic cells. Mol Nutr Food Res. 2008;52(8):921-929.

22. Heng EC, Karsani SA, Abdul Rahman M, Abdul Hamid NA, Hamid Z, Wan Ngah WZ. Supplementation with tocotrienol-rich fraction alters the plasma levels of Apolipoprotein A-I precursor, Apolipoprotein E precursor, and C-reactive protein precursor from young and old individuals. Eur J Nutr. 2013;52(7):1811-1820.

23. Burdeos GC, Nakagawa K, Kimura F, Miyazawa T. Tocotrienol attenuates triglyceride accumulation in HepG2 cells and F344 rats. Lipids. 2012;47(5):471-481.

24. Qureshi AA, Sami SA, Salser WA, Khan FA. Synergistic effect of tocotrienol-rich fraction (TRF(25)) of rice bran and lovastatin on lipid parameters in hypercholesterolemic humans. $J$ Nutr Biochem. 2001;12(6):318-329.

25. Minhajuddin M, Beg ZH, Iqbal J. Hypolipidemic and antioxidant properties of tocotrienol rich fraction isolated from rice bran oil in experimentally induced hyperlipidemic rats. Food Chem Toxicol. 2005;43(5):747-753.

26. Coombes JS, Fassett RG. Antioxidant therapy in hemodialysis patients: a systematic review. Kidney Int. 2012;81(3):233-246.

27. Diepeveen SH, Verhoeven GW, Van Der Palen J, et al. Effects of atorvastatin and vitamin $\mathrm{E}$ on lipoproteins and oxidative stress in dialysis patients: a randomised-controlled trial. $J$ Intern Med. 2005;257(5): 438-445.

28. Uzum A, Toprak O, Gumustas MK, Ciftci S, Sen S. Effect of vitamin E therapy on oxidative stress and erythrocyte osmotic fragility in patients on peritoneal dialysis and hemodialysis. J Nephrol. 2006;19(6): 739-745.

29. Stenvinkel P, Heimburger O, Paultre F, et al. Strong association between malnutrition, inflammation, and atherosclerosis in chronic renal failure. Kidney Int. 1999;55(5):1899-1911.

30. Carrero JJ, Stenvinkel P. Inflammation in end-stage renal disease what have we learned in 10 years? Seminars in Dialysis. 2010;23(5): 498-509.

31. Chin SF, Ibahim J, Makpol S, et al. Tocotrienol rich fraction supplementation improved lipid profile and oxidative status in healthy older adults: a randomized controlled study. Nutr Metab (Lond). 2011;8(1):42.

32. Song BL, DeBose-Boyd RA. Insig-dependent ubiquitination and degradation of 3-hydroxy-3-methylglutaryl coenzyme a reductase stimulated by delta- and gamma-tocotrienols. J Biol Chem. 2006;281(35): 25054-25061.

33. Parker RA, Pearce BC, Clark RW, Gordon DA, Wright JJ. Tocotrienols regulate cholesterol production in mammalian cells by post-transcriptional suppression of 3-hydroxy-3-methylglutaryl-coenzyme A reductase. J Biol Chem. 1993;268(15):11230-11238.

34. Saghaei M. Random allocation software for parallel group randomized trials. BMC Med Res Methodol. 2004;4:26.

35. Daud ZA, Tubie B, Adams J, et al. Effects of protein and omega-3 supplementation, provided during regular dialysis sessions, on nutritional and inflammatory indices in hemodialysis patients. Vasc Health Risk Manag. 2012;8:187-195.

36. Lee JK, Grace KA, Foster TG, et al. How should we measure medication adherence in clinical trials and practice? Ther Clin Risk Manag. 2007;3(4):685-690.

37. Chun J, Lee J, Ye L, Exler J, Eitenmiller RR. Tocopherol and tocotrienol contents of raw and processed fruits and vegetables in the United States diet. J Food Compost Anal. 2006;19:196-204.

38. Piironen V, Syvaoja EL, Varo P, Salminen K, Kaivistoinen P. Tocopherols and tocotrienols in Finnish foods: vegetables, fruits and berries. J Agric Food Chem. 1986;34(4):742-746. 
39. Franke AA, Murphy SP, Lacey R, Custer LJ. Tocopherol and tocotrienol levels of foods consumed in Hawaii. J Agric Food Chem. 2007;55(3): 769-778.

40. Garrow JS, Webster J. Quetelet's index (W/H2) as a measure of fatness. Int J Obesity. 1985;9(2):147-153.

41. World Health Organization. Obesity: Preventing and Managing the Global Epidemic. Geneva: World Health Organization; 2000. Available from: http://libdoc.who.int/trs/WHO_TRS_894.pdf. Accessed October 17, 2013.

42. Bonaccio M, Bonanni AE, Di Castelnuovo A, et al. Low income is associated with poor adherence to a Mediterranean diet and a higher prevalence of obesity: cross-sectional results from the Moli-sani study. BMJ Open. 2012;2(6)

43. Hung A, Pupim L, Yu C, et al. Determinants of C-reactive protein in chronic hemodialysis patients: relevance of dialysis catheter utilization. Hemodial Int. 2008;12(2):236-243.

44. Beerenhout $\mathrm{CH}$, Kooman JP, van der Sande FM, Hackeng C, Leunissen KM. C-reactive protein levels in dialysis patients are highly variable and strongly related to co-morbidity. Nephrol Dial Transplant. 2003;18(1):221.

45. Meuwese CL, Stenvinkel P, Dekker FW, Carrero JJ. Monitoring of inflammation in patients on dialysis: forewarned is forearmed. Nat Rev Nephrol. 2011;7(3):166-176.

46. Yeun JY, Levine RA, Mantadilok V, Kaysen GA. C-Reactive protein predicts all-cause and cardiovascular mortality in hemodialysis patients. Am J Kidney Dis. 2000;35(3):469-476.

47. Blum A, Costello R, Samsel L, et al. Variability of C-reactive protein levels among patients with stable coronary artery disease and on statin therapy. Isr Med Assoc J. 2009;11(10):602-605.

48. Hodkova M, Dusilova-Sulkova S, Kalousova M, et al. Influence of oral vitamin E therapy on micro-inflammation and cardiovascular disease markers in chronic hemodialysis patients. Ren Fail. 2006;28(5): 395-399.

49. Bogaty P, Brophy JM, Boyer L, et al. Fluctuating inflammatory markers in patients with stable ischemic heart disease. Arch Intern Med. 2005;165(2):221-226.

50. Mustad VA, Smith CA, Ruey PP, Edens NK, DeMichele SJ. Supplementation with 3 compositionally different tocotrienol supplements does not improve cardiovascular disease risk factors in men and women with hypercholesterolemia. Am J Clin Nutr. 2002;76(6): 1237-1243.

51. Mensink RP, van Houwelingen AC, Kromhout D, Hornstra G. A vitamin E concentrate rich in tocotrienols had no effect on serum lipids, lipoproteins, or platelet function in men with mildly elevated serum lipid concentrations. Am J Clin Nutr. 1999;69(2):213-219.

52. Kujawa-Szewieczek A, Wiecek A, Piecha G. The lipid story in chronic kidney disease: a long story with a happy end? Int Urol Nephrol. 2013;45(5):1273-1287.
53. Vaziri ND, Norris KC. Reasons for the lack of salutary effects of cholesterol-lowering interventions in end-stage renal disease populations. Blood Purif. 2013;35(1-3):31-36.

54. Zaiden N, Yap WN, Ong S, et al. Gamma delta tocotrienols reduce hepatic triglyceride synthesis and VLDL secretion. J Atheroscler Thromb. 2010;17(10):1019-1032.

55. Rader DJ. Molecular regulation of HDL metabolism and function: implications for novel therapies. J Clin Invest. 2006;116(12): 3090-3100.

56. Glass C, Pittman RC, Weinstein DB, Steinberg D. Dissociation of tissue uptake of cholesterol ester from that of apoprotein A-I of rat plasma high density lipoprotein: selective delivery of cholesterol ester to liver, adrenal, and gonad. Proc Natl Acad Sci U S A . 1983;80(17):5435-5439.

57. Pruijm M, Schmidtko J, Aho A, et al. High prevalence of antiapolipoprotein/A-1 autoantibodies in maintenance hemodialysis and association with dialysis vintage. Ther Apher Dial. 2012;16(6): 588-594.

58. Pahl MV, Ni Z, Sepassi L, Moradi H, Vaziri ND. Plasma phospholipid transfer protein, cholesteryl ester transfer protein and lecithin:cholesterol acyltransferase in end-stage renal disease (ESRD). Nephrol Dial Transplant. 2009;24(8):2541-2546.

59. Aldred S, Sozzi T, Mudway I, et al. Alpha tocopherol supplementation elevates plasma apolipoprotein A1 isoforms in normal healthy subjects. Proteomics. 2006;6(5):1695-1703.

60. Cacciagiu LD, Gonzalez AI, Gomez Rosso L, et al. HDL-associated enzymes and proteins in hemodialysis patients. Clin Biochem. 2012;45(3):243-248.

61. Patel V, Rink C, Gordillo GM, et al. Oral tocotrienols are transported to human tissues and delay the progression of the model for end-stage liver disease score in patients. J Nutr. 2012;142(3):513-519.

62. Fairus S, Nor RM, Cheng HM, Sundram K. Alpha-tocotrienol is the most abundant tocotrienol isomer circulated in plasma and lipoproteins after postprandial tocotrienol-rich vitamin E supplementation. Nutr J. 2012;11:5.

63. Khosla P, Patel V, Whinter JM, et al. Postprandial levels of the natural vitamin E tocotrienol in human circulation. Antioxid Redox Signal. 2006;8(5-6):1059-1068.

64. Fairus S, Nor RM, Cheng HM, Sundram K. Postprandial metabolic fate of tocotrienol-rich vitamin E differs significantly from that of alphatocopherol. Am J Clin Nutr. 2006;84(4):835-842.

65. Yap SP, Yuen KH, Wong JW. Pharmacokinetics and bioavailability of alpha-, gamma- and delta-tocotrienols under different food status. J Pharm Pharmacol. 2001;53(1):67-71. 


\section{Supplementary materials}

Table SI Energy, macronutrient, and micronutrient intake during the course of the study

\begin{tabular}{|c|c|c|c|c|c|c|c|c|}
\hline & \multicolumn{4}{|l|}{ Baseline } & \multicolumn{4}{|l|}{ Week 16} \\
\hline & $\begin{array}{l}\text { All } \\
(n=8 I)\end{array}$ & $\begin{array}{l}\text { Placebo } \\
(n=40)\end{array}$ & $\begin{array}{l}\text { TRF } \\
(n=4 I)\end{array}$ & $P$-value & $\begin{array}{l}\text { All } \\
(n=7 I)\end{array}$ & $\begin{array}{l}\text { Placebo } \\
(n=34)\end{array}$ & $\begin{array}{l}\text { TRF } \\
(n=37)\end{array}$ & $P$-value \\
\hline Energy (kcal/day) & $1,995 \pm 977$ & $2,132 \pm 1,243$ & $\mathrm{I}, 868 \pm 633$ & NS & $\mathrm{I}, 544 \pm 580$ & $\mathrm{I}, 505 \pm 545$ & $1,580 \pm 6 \mid 6$ & NS \\
\hline Protein (g/day) & $94 \pm 59$ & $99 \pm 80$ & $88 \pm 31$ & NS & $75 \pm 40$ & $75 \pm 36$ & $76 \pm 44$ & NS \\
\hline Carbohydrate (g/day) & $209 \pm 106$ & $204 \pm 100$ & $213 \pm 111$ & NS & $178 \pm 79$ & $|77 \pm 7|$ & $180 \pm 85$ & NS \\
\hline Fat (g/day) & $90 \pm 68$ & $105 \pm 90$ & $76 \pm 37$ & NS & $60 \pm 32$ & $57 \pm 23$ & $63 \pm 39$ & NS \\
\hline Vitamin A (IU/day) & $7,37 \mid \pm 19,372$ & $5,524 \pm 7,415$ & $9,172 \pm 26,273$ & NS & $6,015 \pm 9,645$ & $6,377 \pm 12,115$ & $5,718 \pm 7,193$ & NS \\
\hline Vitamin C (mg/day) & $98 \pm 84$ & $89 \pm 82$ & $108 \pm 86$ & NS & $90 \pm 105$ & $102 \pm 112$ & $80 \pm 98$ & NS \\
\hline Vitamin E (mg/day) & $9 \pm 10$ & $9 \pm 9$ & $10 \pm 12$ & NS & $6 \pm 4$ & $5 \pm 3$ & $6 \pm 5$ & NS \\
\hline Tocotrienols (mg/day) & $2.5 \pm 3.8$ & $2.3 \pm 3.8$ & $2.6 \pm 3.8$ & NS & $1.6 \pm 2.3$ & $1.6 \pm 1.5$ & $1.6 \pm 2.8$ & NS \\
\hline Potassium (mg/day) & $2,350 \pm 872$ & $2,329 \pm 1,266$ & $2,37 I \pm 2,334$ & NS & $2,015 \pm 919$ & $|, 962 \pm 96|$ & $2,058 \pm 894$ & NS \\
\hline Phosphorus (mg/day) & $\mathrm{I}, 183 \pm 652$ & $\mathrm{I}, \mid 8 \mathrm{I} \pm 722$ & $1,186 \pm 585$ & NS & $996 \pm 469$ & $953 \pm 431$ & $\mathrm{I}, 03 \mathrm{I} \pm 500$ & NS \\
\hline
\end{tabular}

Notes: Energy, macronutrient, and micronutrient, intake were estimated based on 24-hour dietary recall. Reported tocotrienols values are from diet only and do not include contribution from supplementation. All values are presented as mean \pm standard deviation. $P$-values derived using independent $t$-test, tested for mean differences of micronutrient intake between TRF and placebo groups between baseline and week 16.

Abbreviations: NS, not significant; TRF, tocotrienol-rich fraction.

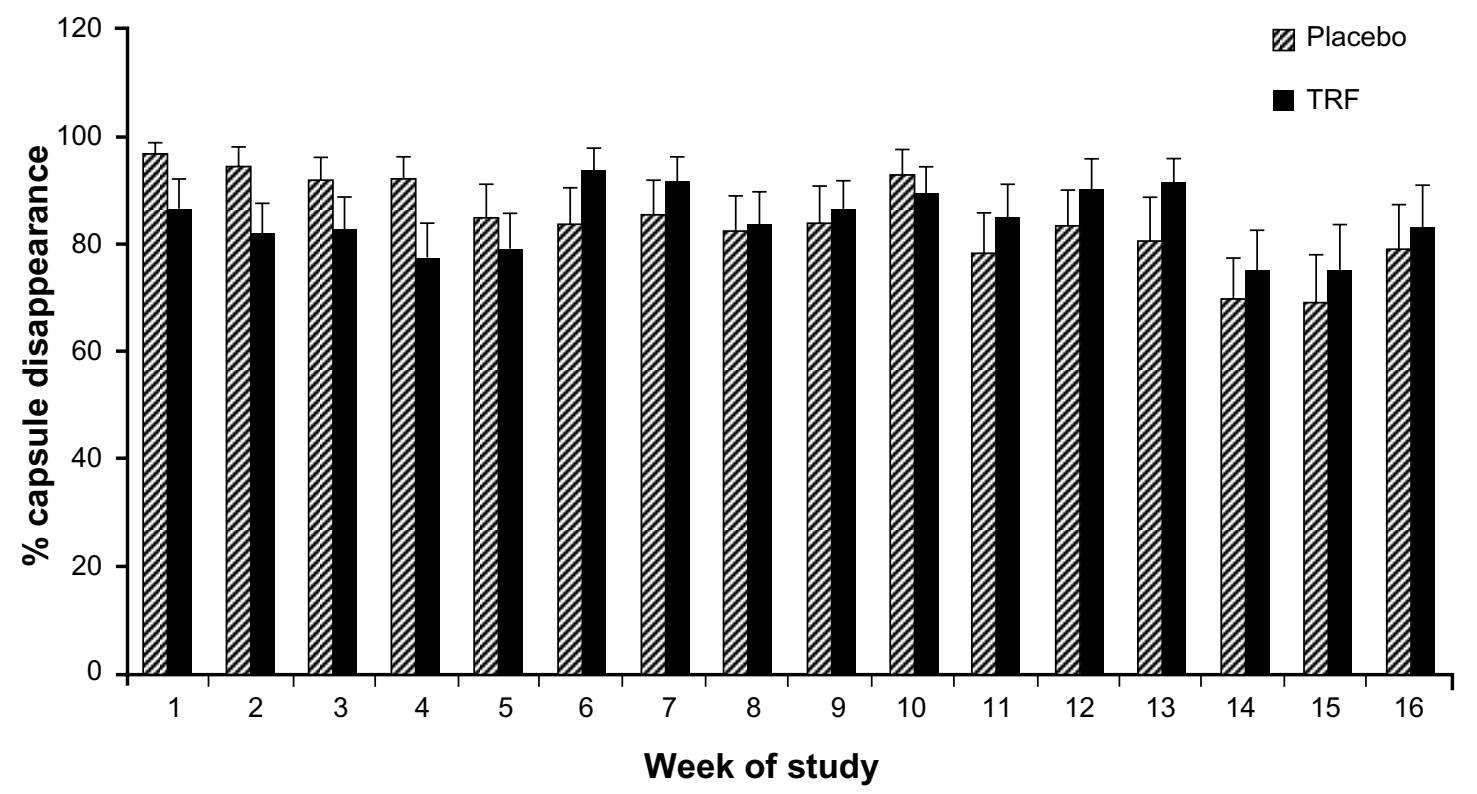

Figure SI Percentage of capsule "consumption" in placebo $(n=38)$ and TRF $(n=40)$ group during the course of the study.

Notes: The figure shows percentage of capsule consumption (disappearance) for non-dialysis days, measured by pill counting method for 16 weeks of the study. Values are expressed as mean \pm standard error of the mean. No significant differences for each week between the two groups were noted, as tested by independent $t$-test. Abbreviation: TRF, tocotrienol-rich fraction. 


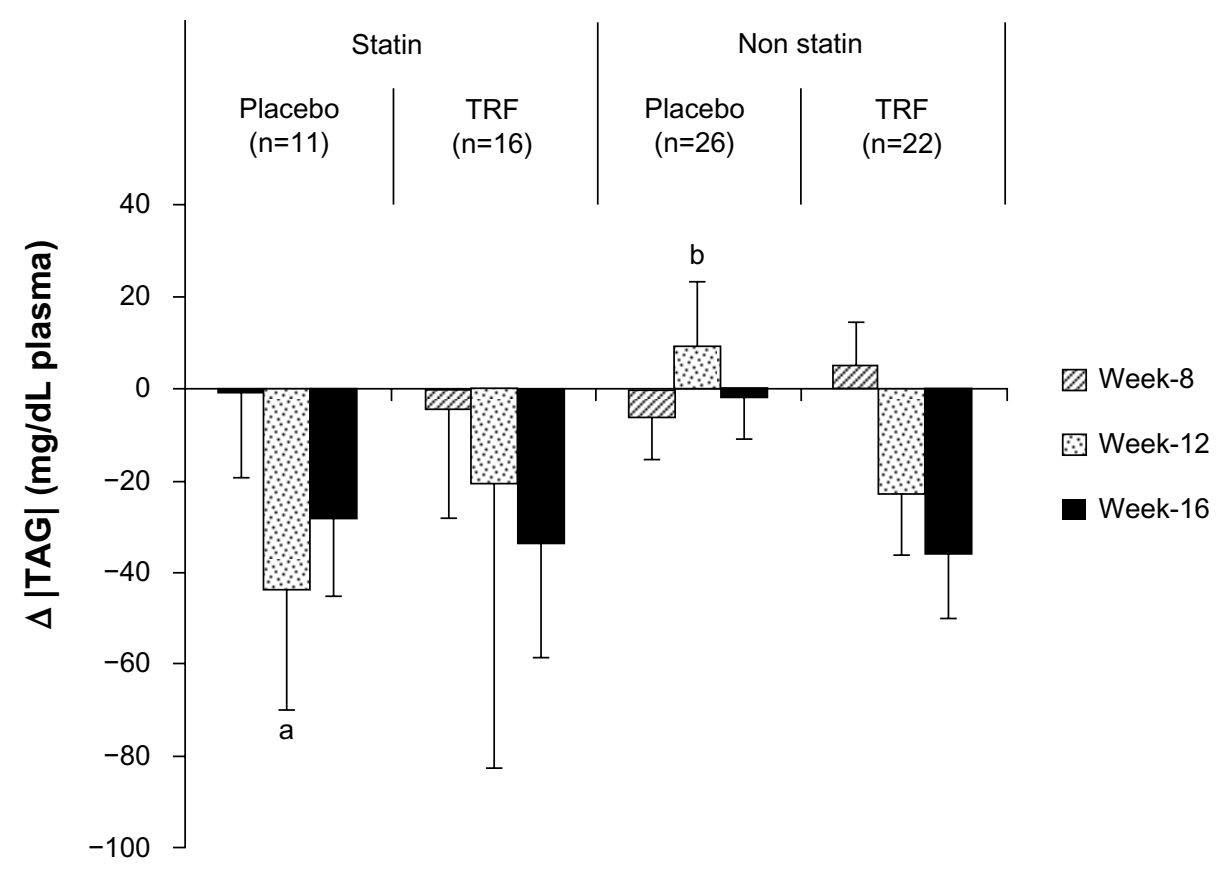

Figure S2 Change in TAG levels among statin and non-statin users in placebo and TRF groups.

Notes: Changes in TAG and HDLC were calculated by deducting baseline values. Data are reported as mean \pm standard error of the mean. a and $b$ denote differing marginal differences $(P<0.08)$, tested by independent $t$-test.

Abbreviations: HDLC, high-density lipoprotein cholesterol; TAG, triacylglycerol; TRF, tocotrienol-rich fraction.

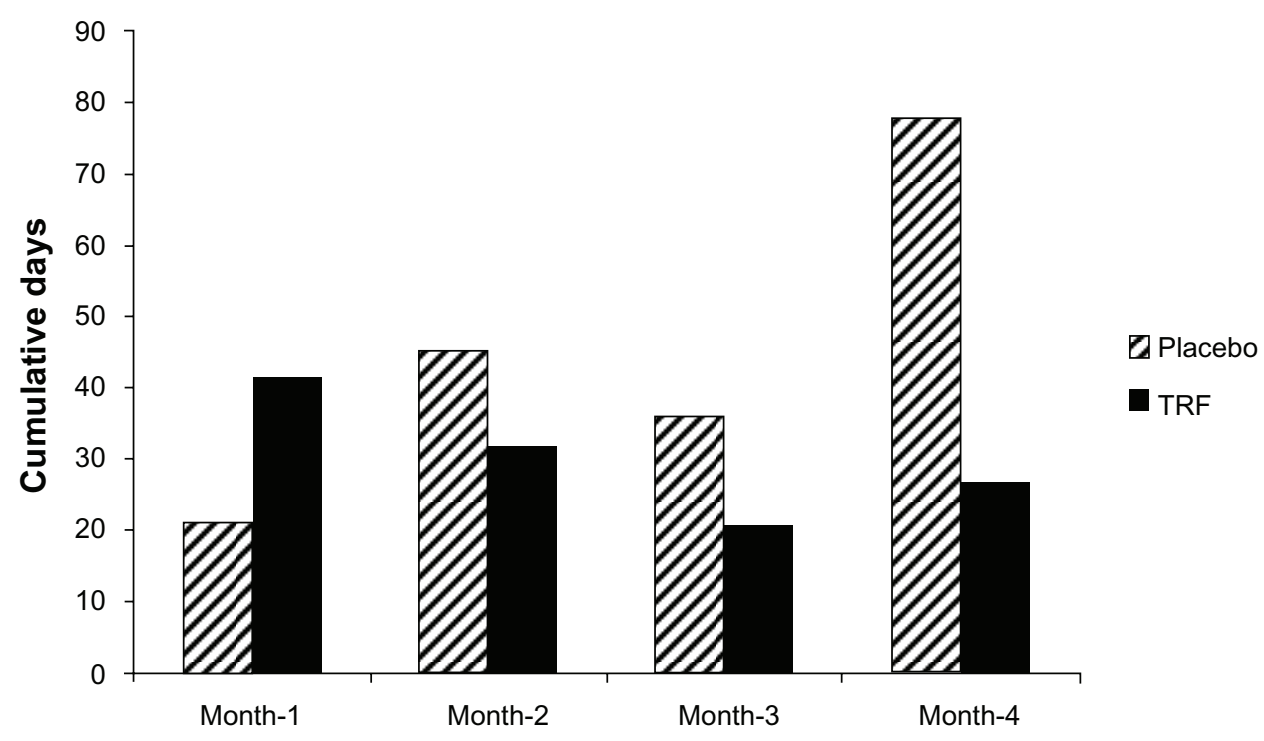

Figure $\mathbf{S} 3$ Cumulative days of missed treatment in placebo $(n=38)$ and TRF $(n=40)$ groups.

Notes: This figure is for illustrative purposes only. Data are presented as absolute number of days of missed dialysis sessions during each month of study course. The total number of days missed was 122 versus 180 for the TRF and placebo groups, respectively.

Abbreviation: TRF, tocotrienol-rich fraction.

Vascular Health and Risk Management

Dovepress

\section{Publish your work in this journal}

Vascular Health and Risk Management is an international, peerreviewed journal of therapeutics and risk management, focusing on concise rapid reporting of clinical studies on the processes involved in the maintenance of vascular health; the monitoring, prevention and treatment of vascular disease and its sequelae; and the involvement of metabolic disorders, particularly diabetes. This journal is indexed on PubMed Central and MedLine. The manuscript management system is completely online and includes a very quick and fair peer-review system, which is all easy to use. Visit http://www.dovepress.com/ testimonials.php to read real quotes from published authors.

Submit your manuscript here: http://www.dovepress.com/vascular-health-and-risk-management-journal 